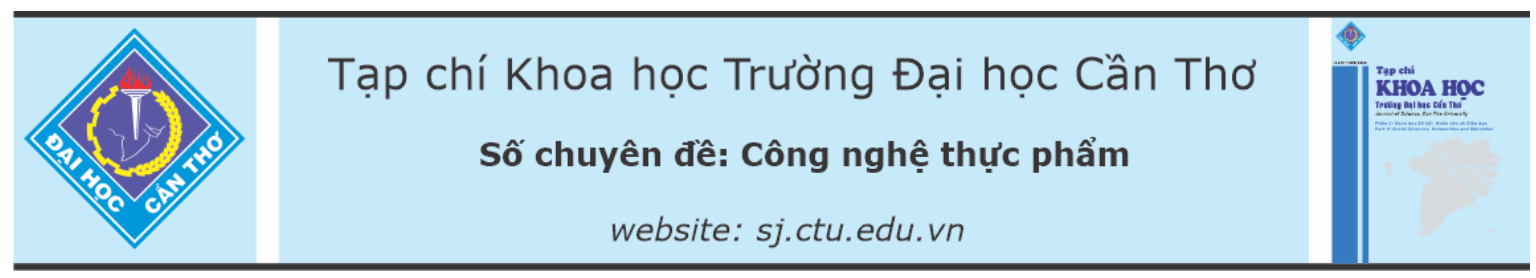

DOI:10.22144/ctu.jsi.2021.017

\title{
ẢNH HƯỞNG CỦA QUÁ TRİ̀H TIỀN XỬ LÝ ĐẾN CHẤT LƯợNG CAM SÀNH (Citrus sinensis) SẤY DẺO
}

Phan Thị Thanh Quế ${ }^{1}$, Dương Kim Thanh ${ }^{1}$, Lê Duy Nghĩa ${ }^{1}$,Nguyễn Lâm Thảo $\mathrm{Vy}^{2}$,

Kha Chấn Tuyền ${ }^{3}$, Nguyễn Văn $\hat{A}^{4}$ và Dương Thị Phượng Liên ${ }^{1 *}$

${ }^{1}$ Bộ môn Công nghệ thưc phẩm, Khoa Nông nghiệp, Truờng Đại học Cần Tho'

${ }^{2}$ Học viên cao học ngành Công nghệ thưc phẩm, Khoa Nông nghiệp, Truờng Đại học Cần Tho

${ }^{3}$ Truò̀ng Đại học Nông Lâm Thành phố Hồ Chí Minh

${ }^{4}$ Bộ môn Sinh lý-Sinh hóa, Khoa Nông nghiệp, Truờng Đại học Cần Tho

*Nguời chịu trách nhiệm về bài viết: Duoong Thị PhuợngLiên (email: dtplien@ctu.edu.vn)

\section{Thông tin chung:}

Ngày nhận bài: $23 / 02 / 2021$

Ngày nhận bài sủa: 13/03/2021

Ngày duyệt đăng: 28/04/2021

\section{Title:}

Effect of pretreatments on the quality of soft dried Sanh orange (Citrus sinensis)

\section{Tù khóa:}

Cam sành, naringin, sấy dẻo, tiền xử lý

\section{Keywords:}

Naringin, pretreatment, Sanh orange, soft drying

\begin{abstract}
Orange fruits contain important natural compounds with diverse biological activities. Developing new products, especially soft dried oragne, which can utilize the abundant amount of orange fruit, and provides a sustainable output for domestic production is become urgent. However, bitterness in certain orange productions is one of the major problems of the orange processing industry. Therefore, research to reduce the bitter taste in dried orange fruit need to be necessary.The objectives of the study were to determine the influence of (i) chemical type ( $\mathrm{NaOH}, \mathrm{Na}_{3} \mathrm{C}_{6} \mathrm{H}_{5} \mathrm{O}_{7}, \mathrm{NaOH}+\mathrm{Na}_{3} \mathrm{C}_{6} \mathrm{H}_{5} \mathrm{O}_{7}, \mathrm{NaCl}$ and $\mathrm{Na}_{2} \mathrm{CO}_{3}$ ) and pretreatment method (soaking and blanching); (ii) concentrations of chemical $(0,50,100,150$ and $200 \mathrm{ppm})$ on the reduction of naringin content and remaining the nutritional value of soft dried Sanh orange. The results showed that the use of $\mathrm{NaOH}(150 \mathrm{ppm})$ as blanching solution gave the highest efficiency in reducing naringin (from 18.75 to 2.11 $\mathrm{mg} / \mathrm{l} 00 \mathrm{~g}$ ). The polyphenol and vitamin C content of sample treated with this condition remained at a high level, $5.57 \mathrm{mgGAE} / \mathrm{g}$ and $71.71 \mathrm{mg} \%$, respectively.
\end{abstract}

\section{TÓM TẮT}

Cam sành là nguồn cung cấp dồi dào hợp chất tư nhiên có hoạt tính sinh học cao. Nghiên cứu phát triển các sản phẩm mới, đặc biệt là sản phẩm cam sấy dẻo, có thể tận dụng nguồn nguyên liệu cam sành dồi dào và cung cấp đầu ra bền vũ̃ng cho sản xuát trong nuơớc là vấn đề cần thiết. Tuy nhiên, vị đắng trong môt số sản phẩm chế biến tù cam là một trong nhũng vấn đề lớn của ngành công nghiẹp chế biến. Do vậy, nghiên cứu giảm vị đắng trong cam sấy dẻo là vấn đề cần thiết. Mục tiêu của nghiên cúu là xác định ảnh hưởng của (i) loại hóa chất xư lý ( $\mathrm{NaOH}, \mathrm{Na}_{3} \mathrm{C}_{6} \mathrm{H}_{5} \mathrm{O}_{7}, \mathrm{NaOH}+\mathrm{Na}_{3} \mathrm{C}_{6} \mathrm{H}_{5} \mathrm{O}_{7}, \mathrm{NaCl} v a ̀$ Na $\left.\mathrm{CO}_{3}\right)$ và phuoong pháp tiền xử lý (ngâm trong dung dịch hóa chất sau đó chần hoặc chần trong dung dịch hóa chất); (ii) ảnh huởng nồng độ của hóa chất xủ lý $(0,50,100,150$ và 200 ppm) đến khả năng giảm hàm lượng naringin và duy trì giá trị dinh duỡng của sản phẩm cam sành sấy dẻo. Kềt quả nghiên cứu cho thấy cam sành được chần trong dung dịch $\mathrm{NaOH}$ với nồng độ 150 ppm giúp giảm được hàm lương naringin cao (tù 18,75 giảm còn 2,11 mg/100g). Hàm lương polyphenol và vitamin $C$ trong sản phẩm vẫn còn duy trì ở mức cao, tuoong úng là $5,57 \mathrm{mgGAE} / \mathrm{g}$ and $71,71 \mathrm{mg} / 100 \mathrm{~g}$. 


\section{1. ĐẶT VẤN ĐỀ}

Cam sành (Citrus sinensis) là loại cây ăn quả quan trọng và phù hợp với điều kiện tự nhiên tại Việt Nam nên được trồng phổ biến khắp ba miền của nước ta, đặc biệt là Đồng bằng sông Cửu Long. Cam sành là cây ăn quả thuộc chi cam chanh, có giá trị dinh dưỡng cao, trong thành phần của nó chứa hàm lượng cao ascorbic acid và hàm lượng tương đối cao một vài hợp chất flavonoid như hesperedin, naringin và naringenin đảm nhận chủ yếu hoạt động chống oxy hóa của cam sành, ngoài ra còn chứa nhiều chất khoáng, chất xơ rất cần thiết cho cơ thể (Abeysingle et al., 2007; Alam et al., 2014). Vitamin C (ascorbic acid) trong họ citrus, đặc biệt cam sành là một trong những chất dỉnh dưỡng quan trọng đối với con người và sự hiện diện của nó có thể ảnh hưởng đến hoạt lực chống oxy hóa ở loại quả này. Hàm lượng ascorbic acid trong các sản phẩm chế biến từ cam quýt khác nhau khoảng $300-450 \mathrm{mg} / \mathrm{L}$ (Lee \& Coates, 1997). Cam sành là nguồn cung cấp dồi dào hợp chất phenolics, đặc biệt là flavonoid với hai thành phần chủ yếu là hesperedin và naringin, là hợp chất góp phần hầu hết vào hoạt tính chống oxy hóa của cam. Hàm lượng hesperedin chiếm khoảng 18,5 $-38,5 \%$ trong tổng số hàm lượng phenolics, trong khi đó naringin chiếm khoảng 53,7\% (Abeysinghe et al., 2007). Ngoài ra, quả cam còn có nhiều tác dụng chống lại bệnh như ung thư, tăng cường sức khỏe tim mạch, giảm huyết áp, chống viêm ( $\mathrm{Li}$ et al., 2006).

Naringin có trong vỏ trắng và cả dịch quả của họ citrus. Hợp chất naringin là hợp chất gây vị đắng cho các sản phẩm được làm từ vỏ. Chất này không chỉ có mặt ở các vỏ quả có múi mà còn chứa trong các màng bao, trong múi. Khi chịu tác động của một tác nhân như nhiệt độ hay thời gian,...thì hai chất neohespendose và rutin (các chất này không gây đắng khi tồn tại ở dạng đơn lẻ) sẽ kết hợp với nhau tạo thành naringin gây ra vị đắng (Gavish et al., 1989). Chất này có nhiều tác dụng sinh học rất mạnh như kháng oxy hóa, giảm lipid máu (Jeon et al., 2001) kháng ung thư và ức chế chọn lọc các enzyme chuyển hóa thuốc cytochrome P450, bao gồm CYP3A4 và CYP1A2, mà có thể gây tương tác thuốc-thuốc trong cơ thể (Ueng et al., 1999). Đặc biệt, là một trong số 21 flavonoid có tác dụng hạ huyết áp, naringin có tác dụng mạnh thứ hai sau rutin. Tuy naringin có tác dụng dược lý rất tốt, nhưng khi chế biến các sản phẩm thực phẩm từ quả họ Citrus thì nó lại gây ra ảnh hưởng xấu cho sản phẩm là tạo ra vị đắng, làm vị của sản phẩm không được hài hòa, từ đó làm giảm giá trị cảm quan của sản phẩm.

Ngưỡng phát hiện của naringin trong dịch quả là $50 \mathrm{mg} / \mathrm{L}$ (Kimball et al., 2005). Naringin tan trong rượu, acetone và nước nóng tan tốt nhất trong nước ở nhiệt độ $75^{\circ} \mathrm{C}$ nhưng lại tan rất ít (khoảng $1 / 2000$ ) ở nhiệt độ $20^{\circ} \mathrm{C}$ và nóng chảy ở $171^{\circ} \mathrm{C}$. Vị đắng trong nguyên liệu có thể giảm đi đáng kể khi nguyên liệu được: ngâm trong dung dịch muối hay phụ gia khác, chần, sử dụng enzyme naringinase (Maier \& Metzler, 1967). Mặt khác, các hoạt chất sinh học đều nhạy cảm với nhiệt độ cao và ánh sáng. Theo nghiên cứu của Bai et al. (2013), quá trình chần với nước xảy ra sự bất hoạt enzyme polyphenoloxydase, làm giảm hàm lượng polyphenol. Bên cạnh đó, vitamin $\mathrm{C}$ cũng là thành phần dễ bị biến đổi nhất trong các loại vitamin khi xử lý nhiệt (Sheetal et al., 2008), chất này không những dễ hòa tan trong nước mà còn bị oxy hóa nhanh, nhất là ở nhiệt độ cao hoặc môi trường kiềm (Emese, 2008). Do vậy, nghiên cứu quá trình tiền xử lý múi cam trước khi sấy giúp giảm bớt vị đắng, tăng giá trị cảm quan, hạn chế tổn thất các thành phần dinh dưỡng khác, đảm bảo chất lượng sản phẩm là điều cần thiết.

\section{PHƯƠNG TIỆN VÀ PHƯƠNG PHÁP NGHIÊN CÚU}

\section{1. Địa điểm nghiên cứu}

Thực hiện nghiên cứu, thu thập số liệu tại phòng thí nghiệm Bộ môn Công Nghệ Thực Phẩm - Khoa Nông Nghiệp, Trường Đại học Cần Thơ

\subsection{Nguyên vật liệu thí nghiệm}

Cam sành thu mua cố định tại vườn thuộc tỉnh Hậu Giang, độ tuổi cây từ 4-6 năm tuổi. Trái cam được thu hoạch ở độ tuổi thuần thục, kích cỡ tương đối đồng đều, không bị sâu bệnh.

\subsection{Phương pháp thí nghiệm}

\subsubsection{Qui trình chế biến cam sành tách múi sấy dẻo tổng quát}

Cam sành sau khi thu mua từ vườn, vận chuyển về phòng thí nghiệm. Cam được rửa với nước sạch, để ráo, gọt vỏ và tách lấy múi cam. Kế đó, múi cam được tiển xử lý với phụ gia/hóa chất và chần giúp giảm vị đắng của cam sành, vô hoạt enzyme hạn chế biến đồi màu, tăng giá trị cảm quan cho sản phẩm. Sau quá trình chần, cam được làm nguội nhanh, để ráo và ngâm trong dung dịch thẩm thấu nhằm tách bớt phần nước trong nguyên liệu, rút ngắn thời gian sấy và tạo cho sản phẩm có mùi vị đặc trưng. Sau đó, cam được vớt ra để ráo, xếp khay và sấy bằng thiết bị sấy đối lưu, nhiệt độ không khí nóng là $60^{\circ} \mathrm{C}$ 
đến khi độ ẩm đạt 18-20\%. Thành phẩm sau sấy được làm nguội, bao gói trong bao bì phức hợp tráng nhôm trước khi phân tích các chỉ tiêu chất lượng sản phẩm.

\subsubsection{Bố trí thí nghiệm}

Thí nghiệm được bố trí trong phòng thí nghiệm, hoàn toàn ngẫu nhiên. Mỗi thí nghiệm được lặp lại ba lần. Thông số tối ưu của thí nghiệm trước được sử dụng cho thí nghiệm sau.

\section{a. Phân tích thành phần hóa lý nguyên liệu}

Xác định thành phần hóa lý của trái cam sành bao gồm độ ẩm, xác định bằng phương pháp sấy ở $105^{\circ} \mathrm{C}$ đến khối lượng không đổi (TCVN 1867:2001); hàm lượng chất khô hòa tan, đo bằng chiết quang kế cầm tay 0-32 ${ }^{\circ} \mathrm{Bx}$ (ATAGO, Nhật) theo phương pháp của AOAC 932.12 (AOAC. 2012); hàm lượng acid tổng số, chuẩn độ bằng $\mathrm{NaOH} 0,1 \mathrm{~N}$ với chất chỉ thị màu phenolphtalein (TCVN 4589:1988); hàm lượng vitamin C, chuẩn độ theo phương pháp Iod (Science Outreach, University of Canterbury, 2020); hàm lượng polyphenol tổng số, xác định theo phương pháp Folin - Ciocateu bằng máy quang phổ UV (Singleton et al., 1999); hàm lượng flavonoid tổng số, đo bằng máy quang phổ UV (Zhu et al., 2010); hàm lượng naringin, sử dụng phương pháp đo độ hấp thụ ở bước sóng $420 \mathrm{~nm}$ theo Davis (1947).

b. Khảo sát ảnh huoơng loại phu gia/hóa chất và phuơng pháp tiền xử lý đến khả năng khư đắng và chất luợng của cam sành tách múi sấy dẻo

Mục đích của thí nghiệm này giúp xác định được loại phụ gia/hóa chất và phương pháp tiền xử lý thích hợp giúp giảm vị đắng múi cam đồng thời hạn chế sự mất thành phần giá trị dinh dưỡng của sản phẩm cam tách múi sấy dẻo.

Thí nghiệm được bố trí ngẫu nhiên với 2 nhân tố và lặp lại 3 lần, nhân tố thay đổi là với các loại phụ gia/hóa chất khử đắng: $\mathrm{NaOH} 100$ ppm, $\mathrm{Na}_{3} \mathrm{C}_{6} \mathrm{H}_{5} \mathrm{O}_{7}$ $0,5 \%, \mathrm{NaOH} 100 \mathrm{ppm}+\mathrm{Na}_{3} \mathrm{C}_{6} \mathrm{H}_{5} \mathrm{O}_{7} 0,5 \%, \mathrm{NaCl}$ $15 \%$ và $\mathrm{Na}_{2} \mathrm{CO}_{3} 0,2 \%$. Cam được xử lý lần lượt với các loại phụ gia/hóa chất này bằng 2 cách: (i) chần với dung dịch phụ gia ở nhiệt độ $85^{\circ} \mathrm{C}$ trong thời gian 1 phút và (ii) ngâm với dung dịch phụ gia trong thời gian 1 giờ, sau đó chần với nước nhiệt độ $85^{\circ} \mathrm{C}$ trong thời gian 1 phút.

Chỉ tiêu theo dõi: hàm lượng naringin, polyphenol tổng số, flavonoid tổng số, vitamin $\mathrm{C}$ của sản phẩm được xác định theo phương pháp như đã trình bày trong mục 2.3.2a.

c. Khảo sát ảnh huởng của nồng độ phu gia/hóa chất chọn lựa tù kết quả thí nghiệm muc đến khả năng khư đắng và chất luợng sản phẩm cam sành tách múi sấy dẻo

Mục đích của thí nghiệm này là xác định nồng độ phụ gia/hóa chất xử lý thích hợp (chọn lựa từ kết quả tối ưu thí nghiệm 1) giúp khử đắng tốt mà vẫn duy trì thành phần giá trị dinh dưỡng và cảm quan của sản phẩm.

Thí nghiệm được bố trí ngẫu nhiên với 1 nhân tố và lặp lại 3 lần, với các mức nồng độ phụ gia/hóa chấtxử lý thay đổi với 5 mức nồng độ và mẫu đối chứng.

Chỉ tiêu theo dõi: hàm lượng naringin, polyphenol tổng số, flavonoid tổng số, vitamin $\mathrm{C}$ và màu sắc sản phẩm được xác định theo phương pháp như đã trình bày trong mục 2.3.2a. Chỉ tiêu cảm quan sản phẩm được đánh giá theo phương pháp mô tả.

\subsection{Phương pháp xử lý số liệu}

Kết quả được xử lý theo phương pháp phân tính phương sai (ANOVA) và kiểm định LSD để kết luận về sự sai khác giữa trung bình các nghiệm thức bằng chương trình STATGRAPHICS Centurion XV.I. Đồ thị được xây dựng bằng chương trình Microsoft Excel 2007.

\section{KẾT QUẢ VÀ THẢO LUẬN}

\subsection{Thành phần hóa lý nguyên liệu trái cam sành}

Thành phần hóa lý trong nguyên liệu là một trong những yếu tố ảnh hưởng đến quá trình chế biến và bảo quản. Vì vậy, phân tích những thành phần có trong nguyên liệu để làm cơ sở xác định các thông số thích hợp trong qui trình chế biến, giúp hạn chế tổn thất chất dinh dưỡng, đảm bảo chất lượng sản phẩm. 
Bảng 1. Thành phần hóa lý của nguyên liệu cam sành

\begin{tabular}{llrr}
\hline Thành phần & Đơn vị & Hàm lượng $(\mathbf{C B U})^{*}$ & Hàm lượng $(\mathbf{C B K})^{*}$ \\
\hline Độ ẩm & $\%$ & $87,86 \pm 0,8$ & \\
${ }^{\circ} \mathrm{Bx}$ & $\%$ & $8,56 \pm 0,61$ & $70,51 \pm 0,61$ \\
Acid tổng số & $\%$ & $0,43 \pm 0,06$ & $3,54 \pm 0,06$ \\
Vitamin C & $\mathrm{mg} \%$ & $31,2 \pm 1,71$ & $257 \pm 1,71$ \\
Polyphenol tổng số & $(\mathrm{mgGAE} / \mathrm{g})$ & $3,54 \pm 0,03$ & $29,19 \pm 0,64$ \\
Naringin & $\mathrm{mg} \%$ & $2,27 \pm 0,08$ & $18,75 \pm 0,35$ \\
Flavonoid tổng số & $\mathrm{mgQE} / \mathrm{g}$ & $0,14 \pm 0,04$ & $1,15 \pm 0,48$ \\
\hline
\end{tabular}

Ghi chú: * Kết quả trung bình của 3 lần lặp lại

Sai số thể hiện trong bảng là độ lệch chuẩn (STD) của giá trị trung bình

Kết quả phân tích thành phần hóa lý nguyên liệu trái cam sành được trình bày ở Bảng 1 cho thấy cam sành là loại trái cây có chứa hàm lượng nước cao $(87,86 \pm 0,8 \%)$. Do vậy, cần có biện pháp chế biến để giảm độ ẩm trái cam sành, giúp kéo dài thời gian bảo quản. Bên cạnh đó, trái cam sành có chứa ${ }^{\circ} \mathrm{Bx}$ tương đối thấp $(8,56 \pm 0,61 \% \mathrm{CBU})$. Do vậy, để giúp cho sản phầm sấy dẻo có vị phù hợp với yêu cầu cảm quan của người tiêu dùng, cần ngâm cam trong dung dịch đường với tỉ lệ thích hợp trước khi sấy. Đồng thời, quá trình ngâm đường giúp tạo sự chênh lệch áp suất thẩm thấu giữa nguyên liệu và dung dịch, tạo điều kiện tách bớt một phần nước trong nguyên liệu, giúp rút ngắn thời gian sấy. Tuy nhiên, hàm lượng acid tổng số trong trái cam sành chiếm tỉ lệ cao $(3,54 \pm 0,06 \% \mathrm{CBK})$. Trái cam sành thuộc nhóm trái cây chứa nhiều dinh dưỡng tốt cho sức khỏe trong đó hàm lượng vitamin $C$ chiếm tỉ lệ cao $(257 \pm 1,71$ $\mathrm{mg} \% \mathrm{CBK})$. Ngoài ra, trong cam sành còn chứa chất có hoạt tính sinh học cao là polyphenol với hàm lượng trung bình 29,19 mgGAE/gCBK, flavonoid với hàm lượng trung bình là $1,15 \pm 0,48 \mathrm{mgQE} / \mathrm{g}$. Đặc biệt naringin là thành phần thuộc nhóm flavonoid chiếm $18,75 \pm 0,35 \mathrm{mg} \%$, đây là thành phần gây vị đắng chính cho sản phẩm. Vì vậy trong chế biến cần chú ý loại bỏ thành phần này để cải thiện và nâng cao chất lượng cho sản phẩm.

\section{2. Ảnh hưởng của loại phụ gia sử dụng và phương pháp tiền xử lý đến chất lượng của sản phẩm cam sành tách múi sấy dẻo}

Phương pháp tiền xử lý và loại phụ gia sử dụng có những ảnh hưởng đến chất lượng sản phẩm cam sành tách múi sấy dẻo. Kết quả được trình bày ở Hình $1,2,3$ và 4 .
Trong quả, naringin như là một glycoside flavonoid, là thành phần đắng chính của một số loại trái cây họ cam quýt (Kimball, 1991) trong đó có cam sành nên sản phẩm có vị đắng nhiều hay ít do naringin quyết định. Kết quả ảnh hưởng của loại phụ gia và phương pháp tiền xử lý đến hàm lượng naringin trong sản phẩm cam sành tách múi sấy dẻo thể hiện ở Hình 1 . Kết quả cho thấy khi xử lý cam sành với các loại phụ gia và phương pháp tiền xử lý khác nhau có ảnh hưởng đến khả năng loại naringin trong múi cam. Trong đó, phương pháp chần trong dung dịch giúp giảm hàm lượng naringin tốt hơn phương pháp ngâm, sau đó chần trong nước. Một số hợp chất flavonoid bị khuếch tán vào nước và bị phân hủy bởi nhiệt độ (Faller \& Fialho, 2009). Naringin là một hợp chất glucoside thuộc nhóm tan trong nước của flavonoid. Khi gia nhiệt ở nhiệt độ cao thì hợp chất này sẽ bị thủy phân thành đường glucose, đường rhamnose. Trong nước nóng dưới tác dụng của nhiệt, sự chuyển động của các phân tử nước tăng lên làm giảm sự tương tác của chúng với nguyên liệu vốn dựa vào liên kết hydro. Do đó, khả năng tiếp xúc với nước của các glucoside tăng, độ hoà tan của các glucoside vào nước cũng tăng lên. Vì vậy khi chần cam trong dung dịch ở nhiệt độ cao làm gia tăng tốc độ hòa tan của naringin vào trong dung dịch nước chần, đồng thời chần trong dung dịch tạo môi trường thẩu thấu cao làm cấu trúc tế bào bị phá vỡ hợp chất naringin theo nước ra ngoài dung dịch chần. So sánh loại phụ gia xử lý đến hàm lượng naringin trong sản phẩm, kết quả cho thấy mẫu chần trong dung dịch $\mathrm{NaOH}$ có hàm lượng naringin còn lại thấp nhất so với khi xử lý với các loại phụ gia khác. 


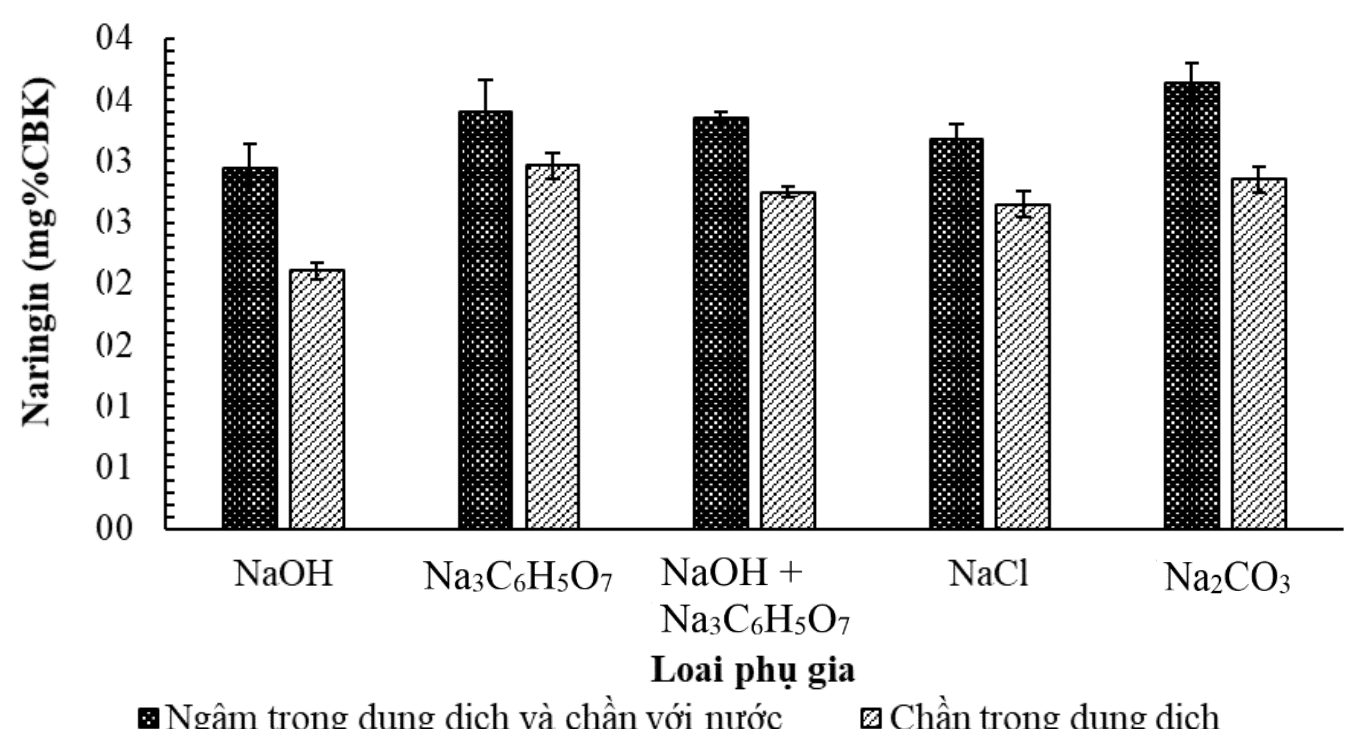

Hình 1. Ảnh hưởng của loại phụ gia và phương pháp tiền xử lý đến hàm lượng naringin trong sản phẩm cam sành tách múi sấy dẻo

Ghi chú: sai số thể hiện ở so đồ hình cột là độ lệch chuẩn (STD) của giá trị trung bình

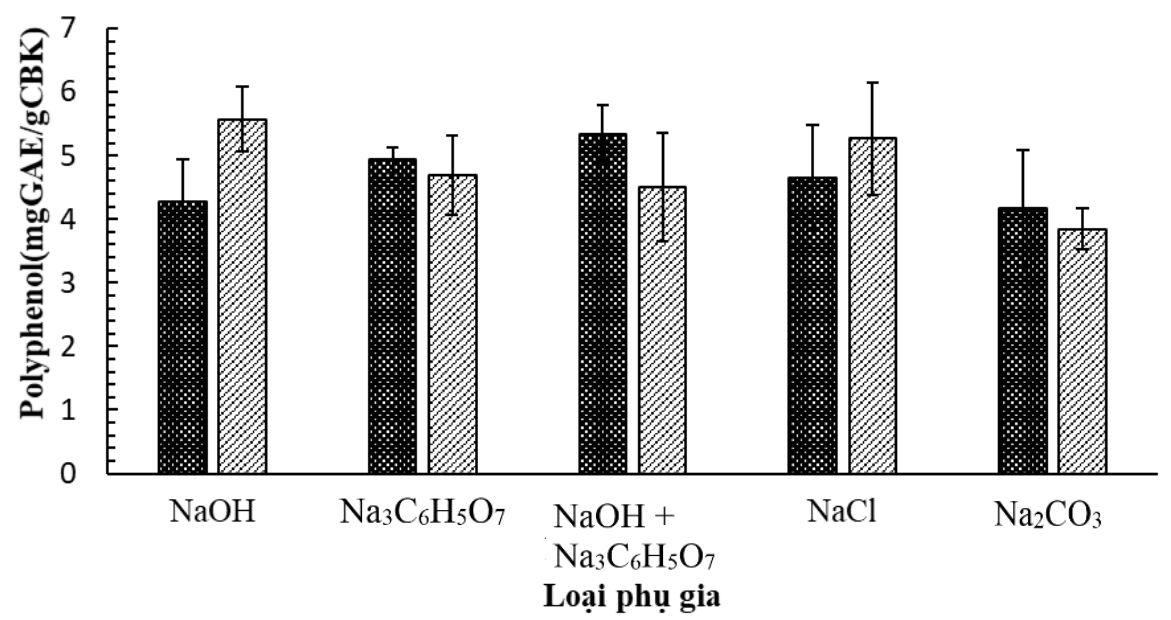

圆 Ngâm trong dung dịch và chần với nước $\quad$ Đ Chần trong dung dịch

Hình 2. Ảnh hưởng của loại phụ gia và phương pháp tiền xử lý đến hàm lượng polyphenol của sản phẩm cam sành tách múi sấy dẻo

Ghi chú: sai số thể hiện ở so đồ hình cột là độ lệch chuẩn (STD) của giá trị trung bình

Hình 2 cho thấy loại phụ gia sử dụngvà phương pháp tiền xử lý có ảnh hưởng đến hàm lượng poyphenol của sản phẩm tính theo căn bản khô. Cụ thề, mẫu chần trong dung dịch $\mathrm{NaOH}$ có hàm lượng polyphenol duy trì cao hơn $(5,57 \mathrm{mgGAE} / \mathrm{g})$ so với mẫu ngâm trong dung dịch $\mathrm{NaOH}$ kết hợp chần với nước $(4,79 \mathrm{mgGAE} / \mathrm{g})$ so với phương pháp chần trong dung dịch $(4,28 \mathrm{mgGAE} / \mathrm{g})$. So sánh các loại phụ gia sử dụng thì mẫu xử lý với $\mathrm{NaOH}$ và $\mathrm{NaCl}$ duy trì hàm lượng polyphenol cao hơn so với các mẫu khác, hàm lượng polyphenol tương ứng là 5,57 và $5,27 \mathrm{mgGAE} / \mathrm{g}$ ) và thấp nhất ở mẫu chần trong dung dịch $\mathrm{Na}_{2} \mathrm{CO}_{3}(3,85 \mathrm{mgGAE} / \mathrm{g})$. Các hoạt chất sinh học này hòa tan trong nước và nhạy cảm với nhiệt độ cao, ánh sáng, đây cũng là nguyên nhân làm suy giảm hàm lượng polyphenol trong sản phẩm. 
Theo Bai et al. (2013), quá trình chần với nước có xảy ra sự bất hoạt enzyme polyphenoloxydase, làm hạn chế sự giảm hàm lượng polyphenol. Tuy nhiên, ở nhiệt độ thích hợp làm cho pholyphenol hòa tan tốt hơn. $\mathrm{Na}_{2} \mathrm{CO}_{3}$ tan trong nước sinh ra nhiệt tạo điều kiện cho polyphenol mất mát nhiều hơn.

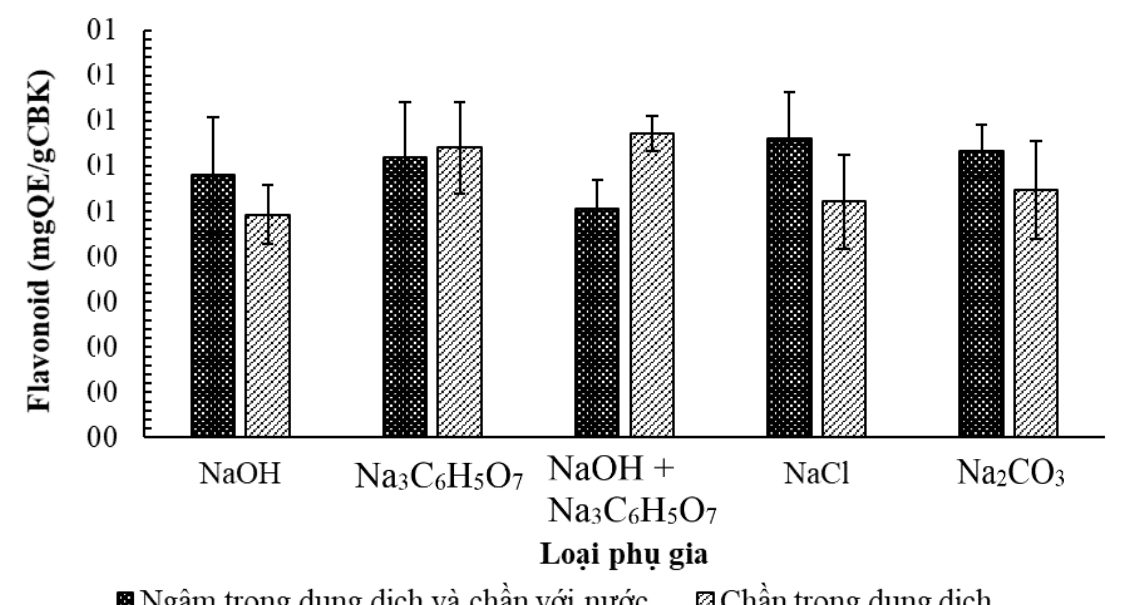

⿴囗大 Nâm trong dung dịch và chần với nước øChần trong dung dịch

\section{Hình 3. Ảnh hưởng của loại phụ gia và phương pháp tiền xử lý đến hàm lượng flavonoid của sản phẩm múi cam sành sấy dẻo}

Ghi chú: sai số thể hiện ở so đồ hình cột là độ lệch chuẩn (STD) của giá trị trung bình

Hình 3 cho thấy phương pháp tiền xử lý và loại phụ gia không có ảnh hưởng đáng kể đến hàm lượng flavonoid của sản phẩm (tính theo căn bản khô), ngoại trừ mẫu xử lý với $\mathrm{NaOH}$ và natri citrat. Hàm lượng flavonoid khi xử lý bằng phương pháp chần trong dung dịch $\mathrm{NaOH}(0,49 \mathrm{mgQE} / \mathrm{g})$ thấp hơn so với phương pháp ngâm trong dung dịch $\mathrm{NaOH}$ sau đó chần với nước $(0,58 \mathrm{mgQE} / \mathrm{g})$. Khi thay đổi các phụ gia khảo sát, hàm lượng flavonoid không có sự thay đổi nhiều, dao động từ $0,5 \mathrm{mgQE} / \mathrm{g}$ đến 0,67
$\mathrm{mgQE} / \mathrm{g}$. Các flavonoid có nhiều nhóm -OH nên dễ tan trong kiềm loãng và các flavonoid glycoside còn tan được trong dung dịch $\mathrm{Na}_{2} \mathrm{CO}_{3}, \mathrm{NaHCO}_{3}$ (do có tính acid) và các dung môi phân cực. Theo Ozogul et al. (2015) và Karabagias et al. (2011),các flavonoid glycoside thường dễ tan trong các dung môi phân cực. Đồng thời khi xử lý trong dung dịch thẩm thấu trong thời gian dài, flavonoid sẽ di chuyển ra dung dịch cùng với việc xử lý ở nhiệt độ cao (chần) cũng góp phần làm giảm flavonoid sản phẩm.

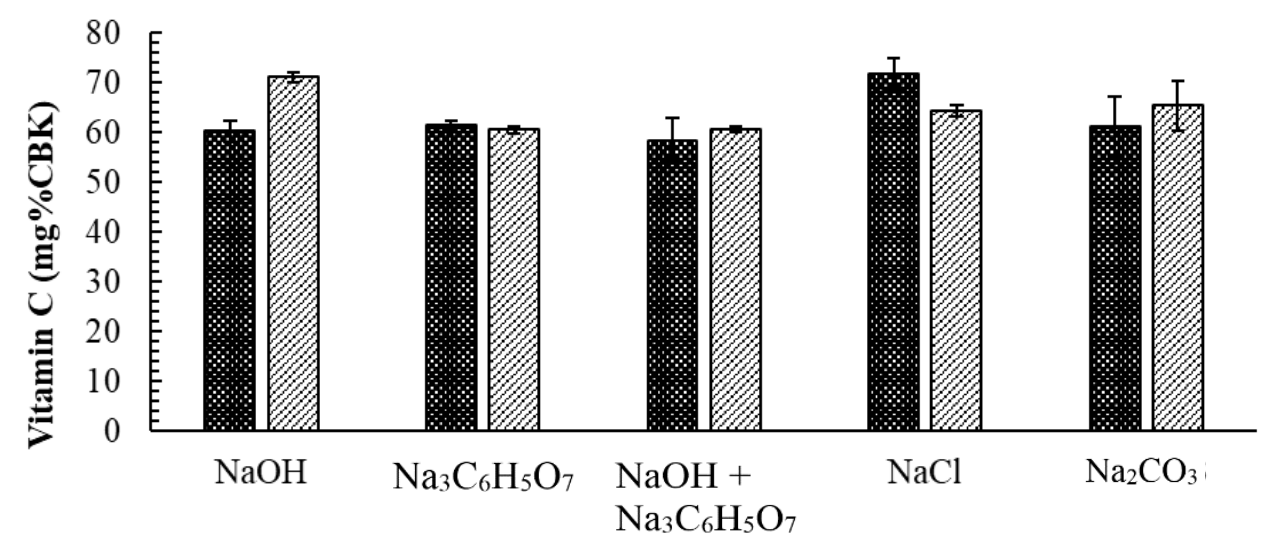

Ngâm trong dung dịch và chần với nước $\quad$ Đ Chần trong dung dịch

Hình 4. Ảnh hưởng của loại phụ gia và phương pháp tiền xử lý đến hàm lượng vitamin $\mathrm{C}$ của sản phẩm cam sành tách múi sấy dẻo

Ghi chú: sai số thể hiện ở so đồ hình cột là độ lệch chuẩn (STD) của giá trị trung bình 
Hình 4 cho thấy các phụ gia sử dụng và phương pháp tiền xử lý có ảnh hưởng đến hàm lượng vitamin $\mathrm{C}$ của sản phẩm sau khi sấy. Với phương pháp ngâm trong dung dịch sau đó chần với nước, mẫu được xử lý với $\mathrm{NaCl}$ có hàm lượng vitamin $\mathrm{C}$ cao nhất $(71,67$ $\mathrm{mg} / 100 \mathrm{~g})$ và thấp nhất là mẫu xử lý với $\mathrm{NaOH} 100$ ppm kết hợp $\mathrm{Na}_{3} \mathrm{C}_{6} \mathrm{H}_{5} \mathrm{O}_{7}$ 0,5\% $(58,41 \mathrm{mg} / 100 \mathrm{~g})$. Trong phương pháp chần với dung dịch, hàm lượng vitamin $\mathrm{C}$ cao nhất và thấp nhất tương ứng với các mẫu được xử lý bằng $\mathrm{NaOH} 100$ ppm và $\mathrm{Na}_{3} \mathrm{C}_{6} \mathrm{H}_{5} \mathrm{O}_{7}$ $0,5 \%$ lần lượt là $71,17 \mathrm{mg} / 100 \mathrm{~g}$ và $60,50 \mathrm{mg} / 100 \mathrm{~g}$.

Vitamin $\mathrm{C}$ dễ bị biến đổi nhất trong các loại vitamin khi xử lý nhiệt (Sheetal et al., 2008), chất này không những dễ hòa tan trong nước mà còn bị oxy hóa nhanh, nhất là ở nhiệt độ cao hoặc môi trường kiềm (Emese, 2008). Vì vậy khi xử lý ngâm và chần trong các dung dịch phụ gia, hàm lượng vitamin $C$ của sản phẩm sau khi sấy giảm đáng kể so với nguyên liệu đầu. Do vitamin $\mathrm{C}$ rất dễ tan trong nước nên khi ngâm 1 giờ trong dung dịch - chần 1 phút với nước thì nó sẽ giảm nhiều hơn khi chỉ chần mẫu trong dung dịch ở thời gian 1 phút. Theo nghiên cứu của Santos \& Silva (2008) trên chíp khoai tây, vitamin $\mathrm{C}$ có thể giảm đến $68 \%$ khi ngâm - chần ở $80^{\circ} \mathrm{C}$ trong 30 phút.

Các kết quả phân tích cho thấy cam sành sấy dẻo được tiền xử lý bằng cách chần với dung dịch $\mathrm{NaOH}$ giúp giảm đáng kể vị đắng trong sản phẩm mà vẫn duy trì hàm lượng polyphenol, flavonoid và vitamin $\mathrm{C}$ ở mức cao.

\section{3. Ảnh hưởng của nồng độ $\mathrm{NaOH}$ xử lý đến khả năng khử đắng và chất lượng của sản phẩm cam sành tách múi sấy dẻo}

Kết quả ảnh hưởng của nồng độ $\mathrm{NaOH}$ trong nước chần đến hàm lượng naringin trong sản phẩm được trình bày ở Hình 5 .

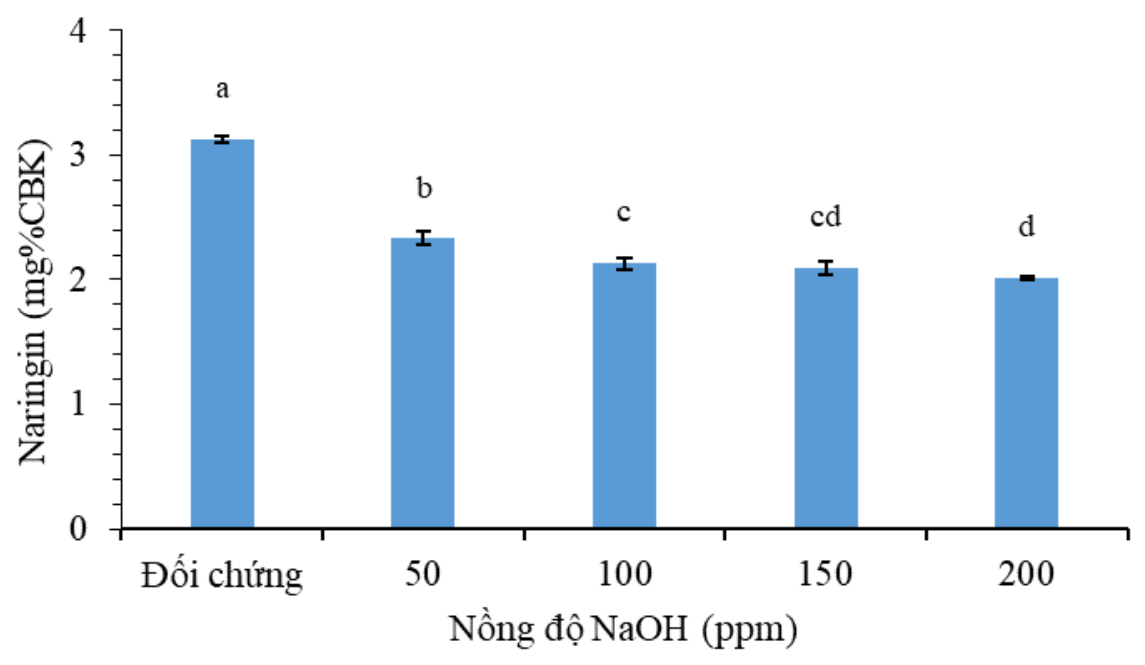

Hình 5. Ảnh hưởng của nồng độ $\mathrm{NaOH}$ trong nước chần đến hàm lượng naringin của sản phẩm

Ghi chú: sai số thể hiện ở so đồ hình cột là độ lệch chuẩn (STD) của giá trị trung bình Mẫu đối chứng là mẫu chần với nuóo c

Hình 5 cho thấy nồng độ $\mathrm{NaOH}$ xử lý có ảnh hưởng đến hàm lượng naringin của sản phẩm, khác biệt có ý nghĩa thống kê $(\mathrm{p}<0,05)$. Khi nồng độ $\mathrm{NaOH}$ trong nước chần tăng, hàm lượng naringin giảm. Cụ thể, hàm lượng naringin cao nhất khi chỉ chần với nước là $3,13 \mathrm{mg} \% \mathrm{CBK}$ và hàm lượng naringin giảm dần khi xử lý với dung dịch $\mathrm{NaOH}$ có nồng độ càng cao; tuy nhiên, hàm lượng naringin trong mẫu xử lý ở nồng độ 200 ppm là 2,02 mg\% giảm rất ít, khác biệt không có ý nghĩa thống kê (p>0,05) so với mẫu xử lý với nồng độ 150 ppm $(2,09 \mathrm{mg} \%)$. Naringin bị hòa tan dễ dàng trong dung dịch kiềm (Trần Thị Định và ctv., 2012), do đó khi nồng độ $\mathrm{NaOH}$ tăng thì hàm lượng naringin trong sản phẩm giảm. Do khi tăng nồng độ $\mathrm{NaOH}$ cao để khử naringin đến một giới hạn, lúc này hàm lượng naringin trong sản phẩm còn lại rất ít thì hàm lượng naringin sẽ không còn giảm đáng kể và hiệu suất khử đắng không còn hiệu quả tốt như lúc đầu. 


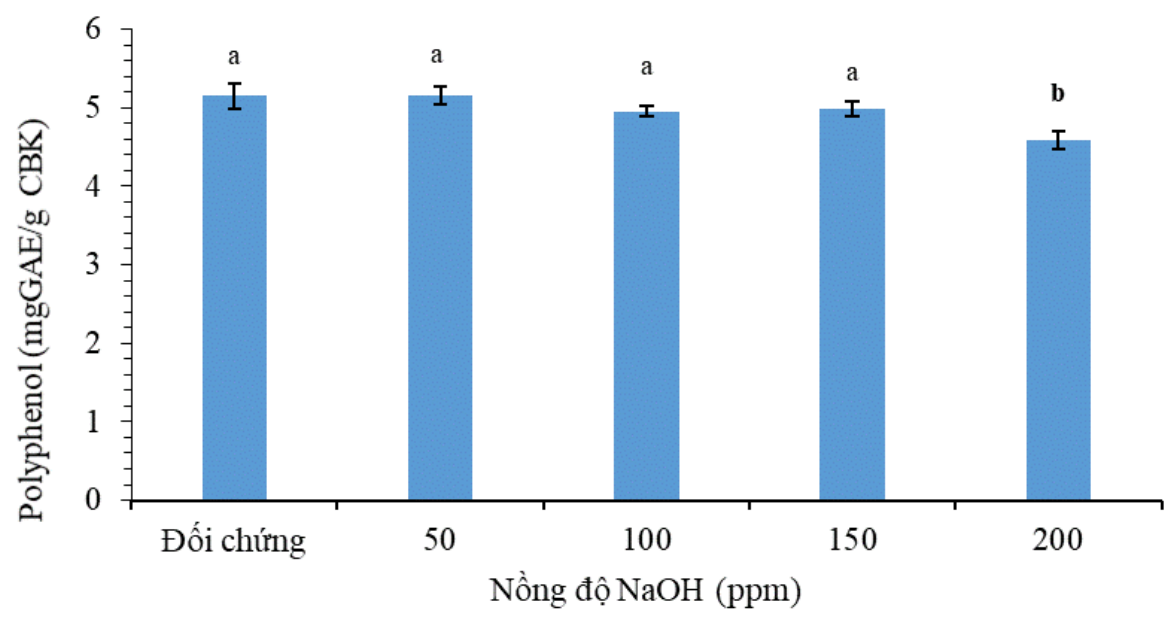

Hình 6. Kết quả ảnh hưởng của nồng độ $\mathrm{NaOH}$ trong nước chần đến hàm lượng polyphenol của sản phẩm

Ghi chú: sai số thể hiện ở sơ đồ hình cột là độ lệch chuẩn (STD) của giá trị trung bình Mẫu đối chứng là mẫu chần với nước

Hình 6 cho thấy nồng độ $\mathrm{NaOH}$ xử lý có ảnh hưởng đến hàm lượng polyphenol của sản phẩm và có sự khác biệt ý nghĩa thống kê giữa các nồng độ $(\mathrm{p}<0,05)$. Nồng độ $\mathrm{NaOH}$ càng tăng thì hàm lượng polyphenol sẽ càng giảm. Cụ thể, khi tăng nồng độ $\mathrm{NaOH}$ xử lý từ 0 đến $200 \mathrm{ppm}$, hàm lượng polyphenol cũng giảm dần từ $5,15 \mathrm{mgGAE} / \mathrm{g}$ xuống còn 4,59 $\mathrm{mgGAE} / \mathrm{g}$.

Quá trình chần có thể thay đổi màu sắc, cấu trúc và hàm lượng chất dinh dưỡng (polyphenol) trong

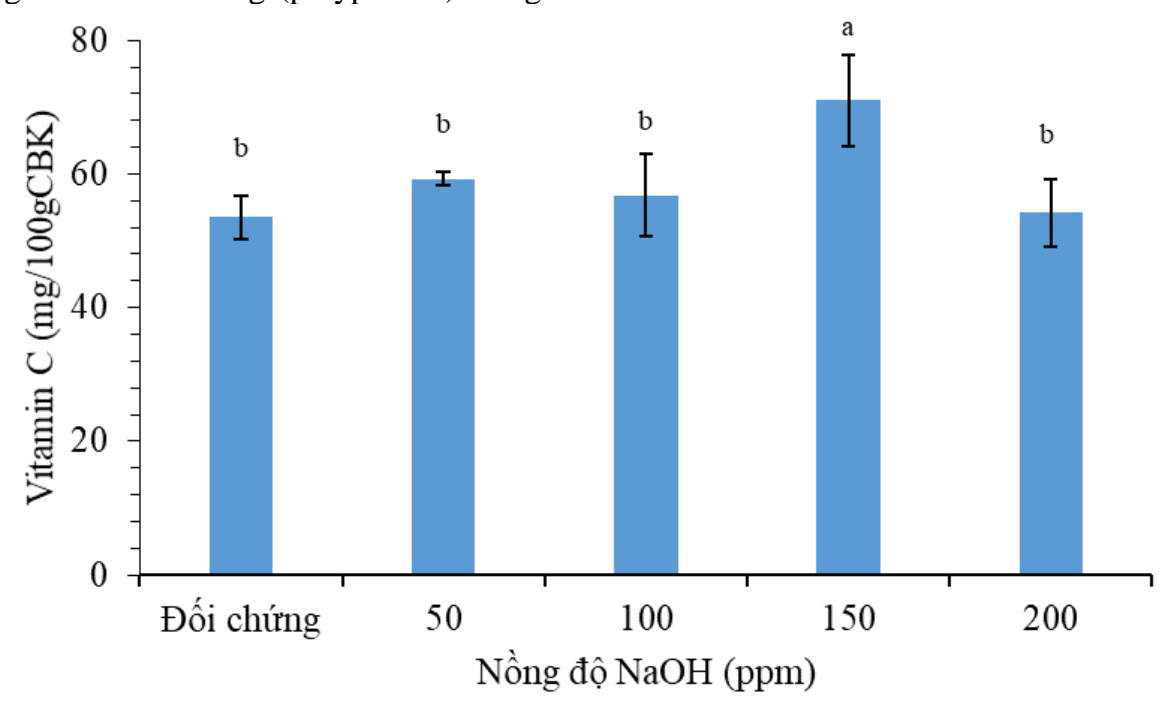

Hình 7. Ảnh hưởng của nồng độ $\mathrm{NaOH}$ trong nước chần đến hàm lượng vitamin $\mathrm{C}$ của sản phẩm

Ghi chú: sai số thể hiện ở so đồ hình cột là độ lệch chuẩn (STD) của giá trị trung bình Mẫu đối chứng là mẫu chần với nước 
Hình 7 cho thấy nồng độ $\mathrm{NaOH}$ xử lý có ảnh hưởng đến hàm lượng vitamin $\mathrm{C}$ của sản phẩm, khác biệt có ý nghĩa thống kê với mẫu xử lý ở nồng độ $200 \mathrm{ppm}(\mathrm{p}<0,05)$. Hàm lượng vitamin $\mathrm{C}$ giảm không nhiều khi tăng nồng độ $\mathrm{NaOH}$, tuy nhiên ở mẫu xử lý với nồng độ 150 ppm có sự tăng hàm lượng vitamin $\mathrm{C}(71,03 \mathrm{mg} / \mathrm{g} \mathrm{CBK})$. Ở mẫu đối chứng, hàm lượng vitamin $\mathrm{C}$ thấp nhất nhất $(53,50$ $\mathrm{mg} / \mathrm{g}$ CBK). pH tối ưu chosự ổn định của acid ascobic là ở trên 6 nhưng dưới 7 (Rahman et al., 1964). Nước sử dụng trong dung dịch chần có giá trị $\mathrm{pH}$ trung tính nên khi nồng độ $\mathrm{NaOH}$ xử lý thấp không ảnh hưởng nhiều đến vitamin $\mathrm{C}$ của sản phẩm, nhưng khi tăng nồng độ $\mathrm{NaOH}$ quá cao $\mathrm{pH}$ của dung dịch xử lý tăng dẫn đến giảm hàm lượng vitamin $\mathrm{C}$ trong sản phẩm.

Bảng 2 cho thấy chất lượng cảm quan về màu sắc, cấu trúc, vị bị ảnh hưởng bởi nồng độ $\mathrm{NaOH}$ trong dung dịch nước chần. Nồng độ $\mathrm{NaOH}$ cao
(100-200 ppm) giúp sản phẩm có màu vàng sáng, khác biệt có ý nghĩa thống kê so với mẫu đối chứng và xử lý với $\mathrm{NaOH}$ nồng độ $50 \mathrm{ppm}$. Tuy nhiên khi xử lý cam trong dung dịch nước chần có nồng độ 200 ppm có điểm cảm quan cấu trúc thấp, khác biệt có ý nghĩa thống kê so với mẫu xử lý với $\mathrm{NaOH}$ nồng độ 100 và $150 \mathrm{ppm}$. Nguyên nhân có thể do nồng độ $\mathrm{NaOH}$ cao tạo ra dung dịch kiềm mạnh và giải phóng nhiệt dễ dàng phá hủy tế bào chất của nguyên liệu làm cho nước trong nguyên liệu thoát ra, khi sấy cùng chế độ, sản phẩm có cấu trúc khô cứng, ít dẻo ảnh hưởng đến điểm cảm quan. Về vị, xử lý cam với nồng độ cao cho giá trị cảm quan càng cao, do hàm lượng naringin trong nguyên liệu được loại bỏ nhiều, sản phẩm giảm vị the đắng, được các cảm quan viên đánh giá cao. Kết quả nghiên cứu của Trần Thị Định và ctv. (2012) trên bưởi cũng cho kết quả tương tự, vị đắng của nguyên liệu giảm rõ rệt khi tăng nồng độ $\mathrm{NaOH}$ chần.

Bảng 2. Ânh hưởng của nồng độ phụ gia xử lý đến chất lượng cảm quan của sản phẩm cam sành tách múi sấy dẻo

\begin{tabular}{crrrr}
\hline Nồng độ NaOH & \multicolumn{3}{c}{ Điểm đánh giá cảm quan } \\
\cline { 2 - 5 }$(\mathbf{p p m})$ & Màu sắc & Cấu trúc & Mùi & Vị \\
\hline Đối chứng & $3,42 \pm 0,41^{\mathrm{a}}$ & $4,00 \pm 0,18^{\mathrm{a}}$ & $3,74 \pm 0,25^{\mathrm{ns}}$ & $2,91 \pm 0,26^{\mathrm{a}}$ \\
50 & $3,91 \pm 0,24^{\mathrm{b}}$ & $4,18 \pm 0,18^{\mathrm{ab}}$ & $3,86 \pm 0,38^{\mathrm{ns}}$ & $3,23 \pm 0,25^{\mathrm{a}}$ \\
100 & $4,21 \pm 0,18^{\mathrm{c}}$ & $4,55 \pm 0,14^{\mathrm{b}}$ & $4,13 \pm 0,11^{\mathrm{ns}}$ & $4,35 \pm 0,16^{\mathrm{b}}$ \\
150 & $4,30 \pm 0,38^{\mathrm{c}}$ & $4,64 \pm 0,21^{\mathrm{b}}$ & $4,20 \pm 0,26^{\mathrm{ns}}$ & $4,38 \pm 0,34^{\mathrm{b}}$ \\
200 & $4,42 \pm 0,26^{\mathrm{c}}$ & $3,98 \pm 0,25^{\mathrm{a}}$ & $3,86 \pm 0,36^{\mathrm{ns}}$ & $4,38 \pm 0,14^{\mathrm{b}}$ \\
\hline
\end{tabular}

Trong cùng một cột, các giá trị có chũ cái theo sau giống nhau thì khác biệt không có ý nghĩa thống kể mức $5 \%$; ns: Khác biệt không có ý nghĩa thống kê $(p>0,05)$

"Mẫu đối chứng là mẫu chần với nước

Trái cam sành có thành phần giá trị dinh dưỡng cao, đặc biệt naringin có tác dụng dược lý rất tốt. Tuy nhiên, naringin tạo vị đắng làm giảm giá trị cảm quan cho sản phẩm. Để khử bớt vị đắng trong quá trình chế biến sản phẩm cam sành tách múi sấy dẻo, cam sau khi được tách múi, chần với dung dịch $\mathrm{NaOH}$ nồng 150 ppm giúp giảm vị đắng của sản phẩm, các thành phần polyphenol, flavonoid và vitamin $\mathrm{C}$ trong sản phẩm vẫn còn duy trì tốt, sản phẩm đạt giá trị cảm quan cao.

\section{LỜI CẢM ƠN}

Bài báo là kết quả từ nghiên cứu khoa học cấp Bộ "Ứng dụng và phát triển một số công nghệ sơ chế, bảo quản và chế biến một số sản phẩm từ cam sành Đồng bằng Sông Cửu Long" (mã số: CT2020.01.TCT.05) thuộc Chương trình khoa học và công nghệ Bộ Giáo dục và Đào tạo. Ban chủ nhiệm đề tài cám ơn sự tham gia nghiên cứu của sinh viên Danh Thị Huỳnh Như (B1600311) và Huỳnh Kim Yến (B1700281).

\section{TÀI LIỆU THAM KHẢO}

Abeysinghe, D. C., Li, X., Sun, C. D., Zhang, W. S., Zhou, C. H. \& Chen, K. S. (2007). Bioactive compounds and antioxidant capacities in different edible tissues of citrus fruit of four species. Food Chemistry, 104(4), 1338-1344.

Alam, M.A., Subhan, N., Rahman, M.M., Uddin, S.J., Reza, H.M. \& Sarker, S.D. (2014). Effect of citrus flavonoids, naringin and naringenin, on metabolic syndrome and their mechanisms of action. Advances in Nutrition,4, 404-417.

AOAC. (2012). Official Methods of Analysis of AOAC International Association of Official Analysis Chemists International.

Bai, J., Gao, Z., Xiao, H., Wang, X.,\& Zhang, Q. (2013). Original article polyphenol oxidase inactivation and vitamin $\mathrm{C}$ degradation kinetics of Fuji apple quarters by high humidity air impingement blanching. International Journal of Food Science and Technology, 48(6), 1135-1141. 
Davis, W. B. (1947). Determination of flavones on citrus fruit. Analytical Chemistry,19(7), 476-478.

Emese, J. N., \& Peter, F. (2008). The stability of vitamin $\mathrm{C}$ in different beverages. British Food Journal, 110 (3), 296-309.

Faller, A., \& Fialho, E. (2009). The antioxidant capacity and polyphenol content of organic and conventional retail vegetables after domestic cooking. Food Research International, 42(1), 210-215.

Gavish, H., Lewinsohn, E., Vardi, A. \& Fluhr, R. (1989). Production of flavanoneneohesperidosidesin citrus embryos. Plant Cell Reports, 8(7), 391-394.

Lee, H. S. \& Coates, G. A. (1997). Vitamin C contents in processed Florida citrus juice from 1986-1995 Survey. Journal of Agricultural and Food Chemistry, 45(7), 2550-2555.

Li, S., Lo, C. Y. \&Ho, C. T. (2006). Hydroxylated polymethoxyflavones and methylated flavonoids in sweet orange (Citrus Sinensis) peel. Journal of Agricultural and Food Chemistry, 54(12), 4176-4185.

Karabagias, I., Badeka, A. \& Kontominas, M. (2011). Shelf life extension of lamb meat using thyme or oregano essential oils and modified atmosphere packaging.Meat Science, 88(1), 109-116.

Kimball, D. A. (1991). Citrus processing: Quality Control Technology. New York: Van Nostrand Reinhold.

Kimball, D., Parish, M. E., \& Braddock, R. (2005). Oranges and Tangerines. In D. M. Barrett, L. Somogyi \& H. Ramaswamy ( $2^{\text {nd }}$ Eds. $)$, Processing fruit science and technology (pp. 623-657). CRC press.

Kidmose, U. \& Martens, H. J. (1999). Changes in texture, microstructure and nutritional quality of carrot slices during blanching and freezing. Journal of the Science of Food and Agriculture, 79(12), 1747-1753.

Maier, V.P. \& Metzler, D.M. (1967). Grapefruit phenolics-I. Identification of dihydrokaempferol and its co-occurrence with naringenin and kaempferol. Phytochemistry, 6, 763-765.

Ozogul, Y., Kuley, E., Ucar, Y., \& Ozogul, F. (2015). Antimicrobial impacts of essential oils on food borne-pathogens. Recent Patents on Food, Nutrition and Agriculture, 7(1), 53-61.

Santos, P. H. S. \& Silva, M. A. (2008). Retention of vitamin $\mathrm{C}$ in drying processes of fruits and vegetables-A Review. Drying Technology, 26(12), 1421-1437.

Science Outreach, University of Canterbury. (2020, 2 20). Determination of vitamin $C$ concentration by a redox titration using iodate, http://www.outreach.canterbury.ac.nz/chemistry/ do cuments/vitaminc_iodate.pdf.

Jeon, S. M., Bok, S. H., Jang, M. K., Lee, M. K., Nam, K. T., Park, Y. B., ... \& Choi, M. S. (2001). Antioxidative activity of naringin and lovastatin in high cholesterol-fed rabbits. Life Sciences, 69(24), 2855-2866.

Sheetal, G., Jyothi L. A.\&Jamuna P. (2008). Effect of different blanching treatments on ascorbic acid retention in green leafy vegetables.Natural Product Radience, 7(2), 111-116.

Singleton, V., Orthofer, R., \& Lamuela-Raventos, R. (1999). Analysis of total phenols and others oxidation substrates and oxidants by means of folin-Ciocaulteau reagent. Methods in Enzymology,299, 152-178.

Rahman, A. R., Anziani, J.\& Cruz-Cay, J. R. (1964). Factors affecting the stability of vitamin $\mathrm{C}$ in tropical fruit juices and nectars. The University of Puerto Rico, 48(1), 1-12.

Trần Thị Định, Nguyễn Thị Nhung, Trần Thị Lan Hương, Đào Thiện và Trần Thị Bích Thủy. (2012). Nghiên cứu quy trình chế biến đồ uống từ bưởi và lô hội. Tạp chí Khoa hoc và Phát triển,10(5), 714-722.

Ueng, Y.F., Chang, Y.L., Oda, Y., Park, S.S., Liao, J.F. \& Chen, C. (1999). In vitro and in vivo effects of naringin on cytochrome P450dependent monooxygenase in mouse liver. Life Sciences, 65(24), 2591-2602. 